\title{
INFESTAÇÕES MACIÇAS POR ACANTOCÉFALOS, Neoechinorhynchus buttnerae GOLVAN, 1956, (EOACANTHOCEPHALA: NEOECHINORHYNCHIDAE) EM TAMBAQUIS JOVENS, Colossoma macropomum (CUVIER, 1818) CULTIVADOS NA AMAZÔNIA CENTRAL
}

\author{
José Celso de Oliveira MALTA, Ana Lúcia Silva GOMES, \\ Sanny Maria Sampaio de ANDRADE, Angela Maria Bezerra VARELLA
}

RESUMO - Os peixes de uma estação de cultivo de tambaquis pararam de se alimentar e começaram a morrer. Um total de 72 peixes foi examinado. Todos os peixes estavam com uma alta infestação intestinal por acantocéfalos. A espécie parasita foi identificada como Neoechinorhynchus buttnerae Golvan, 1956. A prevalência foi de $100 \%$, a intensidade por hospedeiro variou de 30 a 406 e a intensidade média e densidade relativa (abundância) foram de 125,26 . Ocorreu oclusão total do trato intestinal nas altas infestações.

Palavras-chave: Acanthocephala; parasitas de peixes; tambaqui; mortalidade de peixes; aquacultura.

Massive Infestation by Neoechinorhynchus buttnerae Golvan, 1956 (Eoacanthocephala: Neochinorhynchidae) in Young "Tambaquis" Colossoma macropomum (Cuvier, 1818) Cultured in the Central Amazon.

ABSTRACT - The fishes Colossoma macropomum (Cuvier, 1818) from a farm fish stopped to eat and begun to die. Seventy-two fishes caught were examined. All fishes had a high intestinal infestation for Acanthocephala. The species was Neoechinorhynchus butnerae Golvan, 1956. The prevalence was $100 \%$, intensity range 30-406 and mean intensity and relative density (abundance) were 125,26 . In the high infestations occurred the total occlusion of the gut lumen.

Key-words: Acanthocephala; fish parasites; tambaqui; fish mortality; aquaculture.

\section{INTRODUÇÃO}

A partir da década de 60 , o tambaqui, Colossoma macropomum (Cuvier, 1818) tornou-se o mais importante peixe consumido nos centros urbanos da Amazônia, principalmente em Manaus. Em 1976 foi a maior captura, 13.314t. e durante aquela década, esta espécie sozinha foi responsável por mais de $40 \%$ de todo o pescado consumido em Manaus. A captura consistia de peixes adultos que pesavam de 9 a $15 \mathrm{~kg}$. (Petrere, 1978).
Na década de 80 , os desembarques em Manaus variaram de 7.000 a $4.000 \mathrm{t}$. Os pescadores pescavam os tambaquis jovens intensamente, mas os totais capturados nunca alcançaram os valores registrados para adultos nos anos 70 . Na década de 90 , não houve uma queda brusca no tamanho das populações, mas sim uma redução contínua do tamanho do pescado. O $C$. macropomum continua a ser uma das espécies mais importantes explotadas na Amazônia Central e os peixes

Laboratório de Parasitologia e Patologia de Peixes (LPP); Coordenação de Pesquisas em Biologia Aquática (CPBA), Instituto Nacional de Pesquisas da Amazônia (INPA), Caixa Postal 478, Manaus, Amazonas, Brasil, CEP 69011-970. tel. 550926433143. 
jovens constituem a maior parte das capturas comerciais. Não houve quase nenhuma tentativa séria de evitar a pesca de individuos jovens, os peixes adultos são muito mais raros que há uma década atrás e atingem preços muito altos. $\mathrm{O}$ tambaqui tornou-se o peixe símbolo da Amazônia porque ele incorpora uma série de problemas que precisam ser resolvidos para se manejar a pesca e ao mesmo tempo desenvolver a aquacultura (AraujoLima \& Goulding, 1998).

O tambaqui é um dos peixes mais promissores para o cultivo na região Neotropical, por apresentar uma série de características favoráveis, porém um dos problemas a ser resolvido, para que seu cultivo seja viabilizado, é a questão das doenças e parasitas (Benetton \& Malta, 1999). Neste trabalho registramos uma infestação maciça por acantocéfalos em um cultivo de tambaquis.

O Phylum Acanthocephala é formado por helmintos exclusivamente parasitas do intestino de vertebrados. Nove espécies ocorrem nos peixes amazônicos, sendo que duas parasitam o tambaqui: Echinorhynchus jucundus (Travassos, 1923) da família Echinorhynchidae e Neoechinorhynchus buttnerae Golvan, 1956 da Neoechinorhynchidae (Fischer, 1998) .

\section{MATERIAL E MÉTODOS O cultivo}

Um total de 25.000 alevinos de tambaqui foram comprados em uma estação de cultivo no município de Itacoatiara no Estado do Amazonas no dia 13/02/1999. O tamanho dos peixes variava de 1 a $3 \mathrm{~cm}$ e tinham cerca de 30 dias de vida. Foram transportados em sacos plásticos com água com oxigênio para a fazenda de um produtor localizada no $\mathrm{km} 30 \mathrm{da}$ estrada Manaus-Itacoatiara (AM-10). Na propriedade foram colocados em uma barragem nova de 0,75 hectare, para o período de alevinagem, em uma densidade de 3,33 alevinos $/ \mathrm{m}^{2}$.

Após 60 dias (período de alevinagem) os peixes estavam com cerca de $143 \mathrm{~g}$ e foram redistribuídos em quatro barragens $(04 / 1999)$. Cada uma com cerca de 1 hectare de lâmina de água, exceto a primeira que era de 0,75 hectare (barragem (1)). A densidade foi de 2 peixes $/ \mathrm{m}^{2}$, nas barragens de 1 hectare (barragens 2, 3, 4) e 1,5 peixes $/ \mathrm{m}^{2}$ na de 0,75 hectare. As barragens eram interligadas entre si, de modo que a água da barragem (1) era lançada na (2) e assim sucessivamente.

Os peixes foram alimentados com ração extrusada com $34 \%$ de proteina bruta, duas vezes ao dia até $5 \%$ da biomassa do viveiro. Cada barragem era aerada por dois aeradores ligados diariamente das 3 às7 horas e, eventualmente, em dias nublados.

Os parâmetros físico-químicos da água monitorados pelo produtor foram: oxigênio dissolvido; temperatura; saturação de oxigênio; $\mathrm{pH}$ e transparência foram medidos diariamente às 6 e $18 \mathrm{hs}$. A dureza, 
alcalinidade e amônia foram medidos semanalmente às $6,12,18 \mathrm{hs}$.

\section{Amostras analisadas no Laboratório de Parasitologia e Patologia de Peixes.}

Em junho de 1999, os peixes (com cinco meses) da barragem (1) $(0,75$ hectare $)$ pararam de comer e começaram a morrer. No dia 10/vi/ 1999 foram trazidas duas amostras ao Laboratório de Parasitologia e Patologia de Peixes: 26 exemplares da barragem (1); 19 da barragem (2) (por estar conectada a primeira). Os peixes foram necropsiados para determinar a causa das mortes e avaliar as condições de saúde. No dia 24/vi/1999 uma terceira amostragem de 12 peixes e no dia 03/vi/1999 uma quarta de 15 peixes, ambas da barragem (2).

Todos os exemplares foram coletados com rede de arrasto e transportados vivos para o Laboratório de Parasitologia e Patologia de Peixes do INPA, em sacos plásticos contendo água e oxigênio. No laboratório foram transferidos para tanques de concreto, revestidos de azulejos, com água aerada e mantidos vivos, até o momento da necrópsia.

Os peixes foram pesados (em gramas) e medidos (comprimento padrão em centímetros), numerados e todos os dados anotados em uma ficha individual. São dados os valores mínimos, máximos e a média entre parênteses.

Cada peixe foi sacrificado com punção cerebral. A cavidade visceral foi aberta, o trato digestivo totalmente retirado e colocado em uma placa de Petri, cada órgão associado foi examinado separadamente. O canal alimentar foi divido em seções: estômago e esôfago, região pilórica e intestino. $\mathrm{O}$ intestino foi dividido em três partes: anterior, médio e posterior, examinado externamente e dissecado sob microscópio estereoscópio. Os acantocéfalos foram colocados em placas de Petri, com água destilada e mantidos ai até morrerem para que a probóscide e a bursa copulatória ficassem evertidas. Os parasitas foram identificados, contados e foi verificado e registrado a posição, modo de fixação e os danos visiveis à parede da mucosa intestinal.

Quando algum peixe morria e não era possivel fazer a necrópsia imediatamente, estes eram colocados em sacos plásticos etiquetados e congelados. Quando fosse o momento da necrópsia, eram retirados do congelador e deixados descongelar à temperatura ambiente. Os demais procedimentos eram semelhantes. Dez exemplares dos hospedeiros e um lote de 1000 exemplares de acantocéfalos foram depositados na coleção do INPA como material de referência. As medidas tomadas foram feitas com ocular micrométrica e expressas em micrômetros. Os indices parasitários utilizados foram expressos conforme Margolis et al. (1982) e Bush et al. (1997).

\section{RESULTADOS}

Os peixes de uma estação de cultivo de tambaquis pararam de se alimentar e começaram a morrer. Os peixes foram trazidos para o Laboratório de Parasitologia e Patologia de Peixes. Depois de 
necropsiados verificou-se que todos estavam com uma alta infestação intestinal por acantocéfalos. A espécie de Acanthocephala foi identificada como Neoechinorhynchus buttnerae Golvan, 1956. Cada indivíduo foi coletado fixado na mucosa da parede intestinal de seus hospedeiros. Quando a infestação era baixa, somente as regiões dos cecos pilóricos eram parasitadas. A medida que o número de parasitas aumentava, a infestação se estendia para o intestino anterior, médio e posterior. Em altas infestações o trato intestinal ficava totalmente tomado pelos acantocéfalos.

Quando o peixe estava vivo e era sacrificado para a necrópsia, os acantocéfalos eram encontrados vivos no trato intestinal e fortemente fixados na parede intestinal. Se o peixe ao morrer tivesse sido congelado ou fixado para posterior necrópsia, os helmintos encontravam-se soltos no intestino.

Neoechinorhynchus buttnerae encontrava-se fixado à parede intestinal através dos ganchos maiores $\mathrm{da}$ probóscide, localizados na região mais anterior. Estes prendiam-se superficialmente aos tecidos da mucosa intestinal, não sendo observado lesões profundas ou sangramentos. Em alguns casos, cerca de $1 \%$ das áreas de fixação, no local da inserção da probóscide na mucosa do trato intestinal, após a retirada dos helmintos, um pequeno buraco circular com o diâmetro da probóscide era observado. Quando isto acontecia havia destruição de porções da mucosa intestinal.
Grupos de acantocéfalos de 11 a 19 individuos fixavam-se, com suas probóscides, em determinadas áreas da parede do intestino. Cada grupo ocupava toda seção circular da mucosa intestinal disponivel, seus corpos ficavam estendidos em direção à porção posterior. $\mathrm{O}$ próximo grupo fixava-se, de maneira semelhante, a uma distância correspondente ao comprimento total do corpo dos acantocéfalos do grupo anterior e assim sucessivamente por todo o trato intestinal. A vista externa do trato intestinal apresentava áreas de diâmetro maior, que correspondiam as áreas de fixação das probóscides e áreas mais longas, de diâmetro menor, que correspondiam às áreas onde ficavam "flutuando", no lume do intestino, os corpos dos helmintos.

A prevalência foi de $100 \%$, a intensidade por hospedeiro variou de 30 a 406 , e a intensidade média e abundância foram de 125,26 (Tab.1). Devido ao elevado número de indivíduos, verificou-se que estes parasitas causavam oclusão parcial e, nos casos de maiores infestações, oclusão total do trato intestinal, prejudicando a capacidade de absorção e competindo diretamente com o alimento ingerido.

Nos peixes da barragem (1) (Tab. 1) o comprimento padrão variou de $17,0-24,5(20,27) \mathrm{cm}$ e o peso de $195,9-$ $442,94(299,59)$ g. O número de acantocéfalos por peixe, variou de 31$406(125,64)$ individuos. Esta barragem estava interligada às demais, sendo uma fonte constante de 
contaminação da água e dos peixes das barragens situadas à jusante (abaixo). Como não era possivel fazer um tratamento via oral dos peixes, pois não estavam se alimentando $\mathrm{e}$, como outro tipo de tratamento era inviável. Todos os peixes da barragem (1), cerca de 3750 , foram sacrificados e incinerados.

Com a eliminação dos hospedeiros, também foram eliminados os acantocéfalos adultos. Esses parasitavam os peixes e produziam uma grande quantidade de ovos que era ingerida pelos hospedeiros intermediários, que compunham o zooplâncton, fechando assim, o ciclo de vida do parasita, contaminando a água, o plâncton e os peixes das demais barragens. Para eliminar os ovos e as formas jovens que se desenvolviam nos microcrustáceos de vida livre, foi feita a completa secagem da barragem, para submetê-las à dessecação e a ação dos raios ultravioletas da radiação solar. Também foi aplicado a cal virgem $(\mathrm{CaO})$ para a desinfecção.
Nos peixes da barragem (2) (Tab. 1) comprimento padrão variou de $15,0-19,0(16,89) \mathrm{cm}$ e o peso de $131,48-247,28(162,68)$ g. O número de acantocéfalos por peixe variou de 65 $375(74,21)$ indivíduos. Apesar de parasitados, estes peixes não pararam de comer. Na amostra de julho (terceira) doze peixes foram examinados. $\mathrm{O}$ comprimento padrão variou de $16,0-20,5(18,0) \mathrm{g}$. e o peso de $165,06-300,04(226,88) \mathrm{g}$. O número de acantocéfalos por peixe variou de 38-64(120,66). Na amostra de agosto (quarta) quinze exemplares foram examinados. O comprimento padrão variou de $16,0-20,5(21,2) \mathrm{cm}$ e o peso de $137,43-636,05(371,56) \mathrm{g}$. O número de acantocéfalos por peixe variou de 30-177(81,33).

Durante este trabalho o tamanho dos exemplares $N$. buttnerae variou de $16,0-25,5(19,2) \mathrm{mm}$. O número total de peixes examinados (n) foi de 72 .

Nestes peixes foram registrados também a presença de outros grupos de parasitas. O protozoário, Myxobolus sp., apareceu nos rins e na

Tabela 1. Peso, comprimento e indices parasitários de tambaquis jovens (Colossoma macropomum, (Cuvier, 1818)) parasitados por Neoechinorhynchus buttnerae Golvan, $1956 \mathrm{em}$ cultivo semi-intensivo.

\begin{tabular}{|c|c|c|c|c|c|c|c|c|}
\hline $\begin{array}{l}\text { Mês } \\
\text { Coleta }\end{array}$ & Bafragem & $n^{2}$ & $\begin{array}{l}\text { Comprimento } \\
\text { Padrão (cm) }\end{array}$ & Peso (g) & $\begin{array}{c}\text { Prevaléneia } \\
\%\end{array}$ & Intensid ade & $\begin{array}{l}\text { Intensid ade } \\
\text { média }\end{array}$ & $\begin{array}{c}\text { Densid ade } \\
\text { re lativa } \\
\text { a ab undáncia }\end{array}$ \\
\hline 06 & 01 & 26 & $17,0-24,5(20,27)$ & $195,98-442,94(299,59)$ & 100 & $31-406(125,64)$ & 125.64 & 125,64 \\
\hline 06 & 02 & 19 & $15,0-19.0(16,89)$ & $131,48 \cdot 247,28(162,08)$ & 100 & $65-375(174,21)$ & 174,21 & 174,21 \\
\hline 07 & 02 & 12 & $16.0-20.5(18,0)$ & $165.06-300.04(226.88)$ & 100 & $38-264(120,66)$ & 120,66 & 120.66 \\
\hline 08 & 02 & 15 & $16,0-25,5(21,2)$ & $137,43-636,05(371,56)$ & 100 & $30.177(81,33)$ & 81,33 & 81,33 \\
\hline Total & 01,02 . & 72 & $15,0-25,5(21,2)$ & $131,48-636,05(371,56)$ & 100 & $30-406(81,33)$ & 125,26 & 125,26 \\
\hline
\end{tabular}


pele. Os Monogenoidea, Anacanthorus spathulatus Kritsky, Thatcher \& Kayton, 1979 e Linguadactyloides brinkmanni Thatcher \& Kritsky, 1983, da familia Dactylogyridae, foram encontrados nas brânquias e pele. $\mathrm{O}$ copépodo da família Vaigamidae, Gamidactylus jaraquensis Thatcher \& Boeger, 1984, parasitando as fossas nasais. O Branchiura, Argulus chicomendesi Malta \& Varella, 2000, na superficie do corpo. O fungo Saprolegnia sp. na superfície do corpo.

\section{DISCUSSÃO}

Neoechinorhynchus buttnerae foi descrita por Golvan (1956) de treze exemplares coletados no intestino de Colossoma macropomum capturados próximos à Manaus (Thatcher, 1991; Conroy \& Conroy, 1998). O segundo registro foi feito por Schmidt \& Hugghins (1973), que coletaram 20 indivíduos no intestino de um Colossoma nigripinnis (=macropomum) capturado próximo à Letícia, na Amazônia colombiana. O terceiro por Fischer (1998) que coletou 32 tambaquis parasitados no médio rio Solimões, próximo aos municipios de Tefé $\left(3^{\circ} 20^{\prime} 57^{\prime \prime} \mathrm{S}\right.$ e $\left.64^{\circ} 54^{\prime} 37^{\prime \prime} \mathrm{W}\right)$ e Coari $\left(4^{\circ} 6^{\prime} 22^{\prime \prime} \mathrm{S}\right.$ e $63^{\circ} 3^{\prime} 21^{\prime \prime} \mathrm{W}$ ) no Estado do Amazonas. O quarto também foi feito por Fischer (1998) que coletou 5 tambaquis parasitados, no baixo rio Amazonas, próximo ao municipio de Santarém $\left(2^{\circ} 24^{\prime} \mathrm{S}\right.$ e $\left.54^{\circ} 42^{\prime} \mathrm{W}\right)$ no Estado do Pará. Neste trabalho é feito o quinto registro de $N$. buttnerae parasitando o tambaqui, todos os anteriores foram de peixes do ambiente natural. Este é o primeiro registro desta espécie de acantocéfalo parasitando $C$. macropomum em um cultivo.

Ostracoda, Copepoda e larvas de Megaloptera são os hospedeiros intermediários de acantocéfalos da familia Neoechinorhynchidae. Hospedeiros paratênicos (larva de Megaloptera e Mollusca) e hospedeiro secundário opcional (Hirudinea) foram registrados em alguns ciclos conhecidos de neoequinorinquideos (Schmidt \& Hugghins 1973). Todos estes grupos de organismos foram encontrados como itens alimentares no trato digestivo de Pimelodus maculatus Lacépède, 1803 do rio São Francisco, parasitados por $N$. pimelodi Brasil-Sato \& Pavanelli, 1999 (BrasilSato \& Pavanelli, 1999). Devido ao hábito alimentar zooplanctófago dos tambaquis e como os hospedeiros intermediários de $N$. buttnerae fazem parte do plâncton, o ciclo de vida desta espécie de acantocéfala estava completando-se nos cultivos e provocando estas infestações maciças.

Os intestinos de tambaqui coletados no rios Amazonas e Solimões, foram preservados em formol. Posteriormente quando foram necropsiados, os exemplares de $N$. buttnerae encontravam se soltos no lume do trato intestinal (Fischer, 1998). Em nosso trabalho, na maioria das vezes, o peixe estava vivo e era sacrificado para a necrópsia. Os acantocéfalos eram encontrados vivos no trato intestinal, fortemente aderidos na parede do intestino. Quando o hospedeiro examinado tinha sido 
congelado ou fixado, os helmintos eram encontrados soltos no intestino, como no trabalho de Fischer (1998).

A penetração da probóscide dos acantocéfalos na parede intestinal do hospedeiro é o principal dano físico ocasionado pela sua presença. Esta pode ser superficial, profunda ou até mesmo ultrapassá-la, ocasionando lesões sérias. A inserção da probóscide espinhosa, dentro da mucosa do trato intestinal dos peixes, destroi pequenas porções desta e do tecido conectivo. Em alguns casos não há uma patogenicidade marcada, mas em outros, há reações locais severas ao redor do ponto de fixação, que podem ocasionar a perfuração do intestino resultando em uma peritonite (Kabata, 1985).

Em tambaquis jovens, da região de Manaus, enccntrou-se individuos adultos de $N$. buttnerae com até $3 \mathrm{~cm}$ de comprimento. Esta infestação parecia causar oclusão parcial do trato digestivo, interferindo, provavelmente, na capacidade de absorção. Não foi ainda notificado, no entanto, nenhuma reação inflamatória visivel no epitélio (Thatcher, 1991). Em necrópsias de exemplares frescos de tambaquis observou-se que a fixação de $N$. buttnerae no intestino delgado era feita pelos ganchos maiores da probóscide, localizados na região mais anterior. Estes prendiam-se superficialmente aos tecidos da mucosa intestinal, não ocasionando lesões profundas ou sangramentos (Fischer, 1998).

Neste trabalho o tamanho dos exemplares $N$. buttnerae foi de 16,0$25,5(19,2 \mathrm{~mm})$, um pouco menores que os encontrados por Thatcher
(1991). A fixação destes parasitas era feita da mesma maneira encontrada por Fischer (1998), a única diferença, neste caso, foi que os acantocéfalos fixavam-se na parede do intestino dos tambaquis em grupos de 11 a 19 indivíduos, ocupando toda a seção circular da mucosa intestinal disponivel, com os corpos estendidos em direção à porção posterior do intestino, cada grupo fixado a uma distância um pouco maior que o comprimento total do corpo. Este tipo de fixação, agrupados em seções do trato digestivo, indica uma estratégia forçada pela grande quantidade de individuos. Também não foram encontrados sangramentos. Em alguns casos, foi observado na parede do intestino, após a retirada dos helmintos, um pequeno orificio circular com o diâmetro maior que o da probóscide.

No rio Solimões próximos as cidades de Tefé/Coari foram examinados 41 tambaquis, 32 estavam parasitados. A prevalência foi de $78 \%$, a abundância (densidade relativa) 76,7 , a intensidade média de $98,4 \mathrm{e}$ a intensidade variou de 0 a 1549 acantocéfalos por peixe. No rio Amazonas próximo a cidade de Santarém foram examinados 9 tambaquis, 5 estavam parasitados. A prevalência foi de $55,5 \%$, a abundância(densidade relativa) foi de 9,2 , a intensidade média de $16,6 \mathrm{e}$ a intensidade foi de 0 a 67 individuos por peixe. $\mathrm{O}$ comprimento padrão dos hospedeiros foi de 30-150cm (Fischer, 1998).

Embora as condições deste trabalho e o de Fischer (1998) fossem muito diferentes (ambiente natural, lago de várzea $\mathrm{x}$ ambiente de cultivo, 
barragens; peixes jovens $\mathrm{x}$ peixes adultos; reproduzidos naturalmente $\mathrm{x}$ desovas induzidas), foi feito uma comparação, pois o hospedeiro e o parasita são da mesma espécie. Os índices parasitológicos revelaram que nos cultivos a prevalência sempre foi maior: $100 \%$ contra $78 \%$ e $55,5 \%$. A intensidade variou de 31 a 406 individuos (0-1549 e 0-67), o limite inferior foi 31 vezes maior, enquanto que o superior foi cerca de 4 vezes menor que no ambiente natural. Isto porque Fischer (1998) encontrou uma correlação positiva entre o comprimento total do tambaqui e o número de acantocéfalos (quanto maior o peixe maior o número de parasitas). Como nos cultivos, os peixes eram jovens e o tamanho variou apenas de 5,0$25,5(21,2)$, não houve tempo suficiente para os hospedeiros atingissem maiores tamanhos e ficassem expostos a maiores infestações, para se chegar aos altos números de intensidade encontrados em peixes adultos. A abundância (densidade média) no ambiente natural foi 9,2-76,7 $(42,95)$ e nos tanques de cultivo variou de $81,33-174,21(125,46)$, sendo muito mais altas no ambiente confinado. Nos cultivos a abundância(densidade média) foi igual a intensidade média pois o número de peixes parasitados era igual ao de examinados.

Entre os helmintos que parasitam os peixes os acantocéfalos são, talvez, o grupo que possui menos importância no que se refere aos prejuízos determinados em seus hospedeiros. No Brasil praticamente não existem relatos de casos de mortalidade de peixes de cultivo associados aos acantocéfalos, já que as lesões produzidas por estes parasitas ficam restritas ao local de fixação (Pavanelli et al.,1998). Não se tem conhecimento de nenhum caso de acantocéfalos registrados como problema patológico no cultivo de Colossoma na América Latina (Conroy \& Conroy, 1998). A importância dos acantocéfalos para a aquacultura nunca foi suficientemente alta para promover o desenvolvimento de medidas e controles específicos. Procedimentos gerais de profilaxias são considerados suficientes para prevenir sérias infecções. Controle do suprimento de água e de potenciais hospedeiros intermediários, como quarentenas geralmente dão bons resultados (Kabata, 1985).

Neste trabalho registramos um grave problema patológico, que culminou com a morte do hospedeiro, ocasionado por acantocéfalos, em um cultivo de C. macropomum. A epizootia iniciou com a compra de alevinos parasitados. Com o desenvolver do cultivo e da infestação houve um crescimento mais lento dos peixes, quando comparado com os cultivos anteriores a seguir pararam de comer e culminando com a morte. Ocorreu uma infestação maciça, com todos os jovens tambaquis com o intestino repleto de $N$. buttenerae. O problema ocorreu porque não houve uma avaliação prévia das condições de sanidade dos alevinos ao serem adquiridos, não houve um período de quarentena e tecnicamente as barragens estavam construídas inadequadamente, isto é, interligadas entre si. 
A fauna de parasitas do tambaqui conhecida é formada por representantes de vários grupos. As bactérias Aeromonas hydrophila; Pseudomonas spp.; Flexibacter colunnaris; Mycobacterium spp. (Bermudez, 1980 apud Conroy \& Conroy, 1998). Fungos Saprolegnia sp. Os protozoários; Henneguya sp., Myxobolus sp. (Thatcher, 1991; Eiras et al., 1995; Conroy \& Conroy, 1998), Ichthyophthirius multifilis, Trichodina sp., Apiosoma sp. (Eiras et al., 1995; Conroy \& Conroy, 1998), Cryptobia sp., I. necator e Amoeba (Eiras et al., 1995).

Os helmintos Monogenoidea: Anacanthorus spatulatus Kritsky, Thatcher \& Kayton, 1979, Linguadactyloides brinckmanni Thatcher \& Kritsky, 1983 e Notozothecium sp. (Thatcher, 1991; Conroy \& Conroy, 1998, Fischer, 1998). Trematoda Digenea: jovens da família Paramphistomidae (Fischer, 1998). Nematoda: Spirocamallanus inopinatus Travassos, 1929, Spirocamallanus spp. (Ferraz, 1995), Spirocamallanus sp. e Procamallanus sp. (Fischer, 1998). Cestoda, plerocercóides (Khon, et al., 1985).

Os crustáceos: Branchiura: Dolops carvalhoi Castro, 1949, Argulus multicolor Sthekhoven, 1937 e A. chicomendesi Malta \& Varella, 2000 (Malta, 1983; 1984; Malta \& Varella $1983 ; 2000)$. Copepoda: Gamidactylus jaraquensis Thatcher \& Boeger, 1984 (Fischer, 1998) e Perulernaea gamitanae Thatcher \& Paredes, 1985 (Benetton \& Malta, 1999). Isopoda, Braga sp. (Varella, comunicação pessoal).

Além de $N$. buttnerae encontramos outras espécies que já eram conhecidas como parasitas do tambaqui em cultivos na região, no Sudeste do Brasil e em outros países da América do Sul. Os protozoários Myxobolus sp. parasita dos rins e da pele, os Monogenoidea Anacanthorus spatulatus e Linguadactyloides brinckmanni das brânquias e pele. $\mathrm{O}$ copépodo da familia Vaigamidae Gamidactylus jaraquensis das fossas nasais, o Branchiura Argulus chicomendesi da superfície do corpo e o fungo Saprolegnia sp. da superfície do corpo.

Com o aumento dos cultivos intensivos e semi intensivos de tambaquis e outros peixes, na região Amazônica, muito cuidado tem que se ter com a prevenção das doenças. Há uma fauna de animais que utilizam o peixe como substrato e vivem em equilíbrio com o hospedeiro. Quando os peixes são mantidos em cativeiro, são submetidos a grandes estresses resultantes, da captura, transporte, manuseio, alta densidade, qualidade da água com excesso de compostos tóxicos, baixa quantidade de oxigênio, $\mathrm{pH}$ e temperaturas com grandes variações, falta, deficiência, excesso ou alimentação inadequada, instalações deficientes, desinfecções, reprodução artificial, mão-de-obra sem preparo. Estes fatores alteram a homeostasia do peixe tornando-os mais sensiveis e com menor resistência aos patógenos. $\mathrm{O}$ equilíbrio que existia entre o hospedeiro e sua fauna simbionte é quebrado surgindo as epizootias, que são de difícil controle e normalmente levam os 
peixes à morte em pouco tempo.

\section{AGRADECIMENTOS}

Agradecemos ao técnico do Laboratório de Parasitologia e Patologia de Peixes, Edilson de Araújo Silva pelo auxílio na necrópsia dos peixes. Ao pesquisador da EMBRAPA, Antônio Cláudio Uchôa Izel, pela comunicação do problema, fornecimento dos peixes e todos os dados de manejo do cultivo.

\section{Bibliografia citada}

Araujo-Lima, C.; Goulding, M. 1998. Os frutos do tambaqui: ecologia, conservação $e$ cultivo na Amazónia. Lithera Ed., Sociedade Civil Mamirauá, CNPq, Tefé, AM, Brasil. 186p.

Benetton, M.L.F.N; Malta, J.C.O. 1999. Morfologia dos estágios de náuplios e copepodito I de Perulernaea gamitanae Thatcher \& Paredes, 1985 (Crustacea: Cyclopoida: Lernaeidae), parasita do tambaqui Colossoma macropomum (Cuvier, 1818), (Osteichthyes: Characidae), cultivados em laboratório. Acta Amazonica, 29(1):97-121.

Brasil-Sato, M.C.; Pavanelli, G.C. 1999. Ecological and reproductive aspects of Neoechinorhynchus pimelodi Brasil-Sato \& Pavanelli (Eoacanthocephala, Neoechinorhynchidae) of Pimelodus maculatus Lacépède (Siluroidei, Pimelodidae) of the São Francisco River, Brazil. Revista Brasileira de Zoologia, 16(1):73-82.

Bush, A.O.; Lafferty, K.D.; Lotz, J.M.; Shostak, A.W. 1997. Parasitology meets ecology on its own terms: Margolis et al. Revisited. Journal Parasitology, 83(4):575-583.

Conroy, G.; Conroy, D. A., 1998. Enfermidades y parasitos de cachamas, pacus y tilapias. Documento Tecnico n. ${ }^{9}$ 3. UDATPA, Pharma-Fish S.R.L. Maracay, Venezuela. p.7-65.
Eiras, J.C.; Ranzani-Paiva, M.J.T.; Ishikawa, C.M.; Alexandrino, A.C.; Eiras, A.C. 1995. Ectoparasites of semi-intensively farmed tropical fish Piaractus mesopotamicus, Prochilodus lineatus and Colossoma macropomum in Brazil. Bulletin of European Association of Fish $\mathrm{Pa}$ thology, 15(5):148-151.

Fischer, C. 1998. A fauna de parasitas do tambaqui Colossoma macropomum (Cuvier, 1818) (Characiformes: Characidae) do médio rio Solimões(AM) e baixo rio Amazonas(PA) e seu potencial como indicadores biológicos. Dissertação de mestrado. Instituto Nacional de Pesquisas da Amazônia, Fundação Universidade do Amazonas. Manaus, Brasil. 63p.

Kabata, Z, 1985. Parasites and diseases of fishes cultured in the tropics. Taylor \& Francis, London, UK. 318p.

Khon, A.; Fernandes, B.M.M.; Macedo, B.; Abramson, B. 1985. Helminthes parasites of freshwater fishes from Pirassununga, SP, Brasil. Memórias do Instituto Oswaldo Cruz, 80:327-336.

Malta, J.C.O. 1983. Os argulídeos (Crustacea: Branchiura) da Amazônia brasileira, 4. Aspectos da Ecologia de Argulus multicolor, Stekhoven 1937 e A. pestifer Ringuelet 1948. Acta Amazonica, 13(34):489-496.

Malta, J.C.O., 1984. Os peixes de um lago de várzea da Amazônia Central (Lago

Janauacá, Rio Solimões) e suas relaçōes com os crustáceos ectoparasitas (Branchiura: Argulidae). Acta Amazonica, 14(3-4):355-372.

Malta, J.C.O; Varella, A. 1983. Os argulídeos (Crustacea: Branchiura) da Amazônia brasileira, 3. aspectos da Ecologia de Dolops striata Bouvier, 1899 e $D$. carvalhoi Castro, 1949. Acta Amazonica, 13(2):299-306.

Malta, J.C.O.; Varella, A.M.B. 2000. Argulus Chicomendesi sp. n. (Crustacea: Argulidae) parasita de peixes da Amazônia brasileira. Acta Amazonica, 30(3):no prelo Margolis, L.; Esch, G.W.; Holmes, J.C.; Kuris, 
A. M.; Schad, G.A. 1982. The use of ecological terms in Parasitology (Report of an ad hoc Committee of the American Society of parasitologists). Journal of Parasitology, 68(1):131-133.

Pavanelli, G.C.; Eiras, J.C.; Takemoto, R.M. 1998. Doenças de Peixes: Profilaxia, Diagnóstico e Tratamento. EDUEM: Universidade Estadual de Maringá, Nupélia, Maringá, Brasil. 264p.

Petrere, M. 1978. Pesca e esforço de pesca no Estado do Amazonas. II. Locais, aparelhos de captura e estatística de desembarque. Acta Amazonica, 8(3):1-53. (supl. 2).

Schmidt, G.D.; Hugghins, E.J. 1973. Acanthocephala of South American Fishes. Part I, Eoacanthocephala. Journal of Parasitology, 59(5):829-835.

Thatcher, V.E. 1991. Amazon fish parasites. Amazoniana, 11(3-4):263-572. 